\title{
Clinical significance of stanniocalcin 2 expression as a predictor of tumor progression in gastric cancer
}

\author{
TAKAAKI ARIGAMI ${ }^{1}$, YOSHIKAZU UENOSONO ${ }^{2}$, SUMIYA ISHIGAMI $^{1}$, SHIGEHIRO YANAGITA $^{1}$, \\ TAKAHIKO HAGIHARA ${ }^{1}$, NAOTO HARAGUCHI ${ }^{1}$, DAISUKE MATSUSHITA ${ }^{1}$, TETSUSHI HIRAHARA ${ }^{1}$, \\ HIROSHI OKUMURA ${ }^{1}$, YASUTO UCHIKADO ${ }^{1}$, AKIHIRO NAKAJO ${ }^{1}$, SHUICHI HOKITA $^{3}$ and SHOJI NATSUGOE ${ }^{1,2}$ \\ ${ }^{1}$ Department of Digestive Surgery, Breast and Thyroid Surgery, Field of Oncology and ${ }^{2}$ Molecular Frontier Surgery, \\ Course of Advanced Therapeutics, Kagoshima University Graduate School of Medical and Dental Sciences; \\ ${ }^{3}$ Department of Surgery, Jiaikai Imamura Hospital, Kagoshima, Japan
}

Received July 11, 2013; Accepted September 2, 2013

DOI: 10.3892/or.2013.2775

\begin{abstract}
Stanniocalcin 2 (STC2) is a glycoprotein hormone that plays an important role in calcium and phosphate homeostasis. Furthermore, recent studies have demonstrated that STC2 expression in the primary site is correlated with tumor progression in several types of malignancies. However, few reports have investigated the clinical significance of STC2 expression in the blood of patients with gastric cancer. Therefore, we examined STC2 expression as a molecular blood marker for detection of circulating tumor cells (CTCs) and assessed the relationship between STC2 expression and clinicopathological features including prognosis in patients with gastric cancer. Quantitative PCR assay was used to assess STC2 mRNA expression in 4 gastric cancer cell lines and in blood specimens from 93 patients with gastric cancer and 22 healthy volunteers. The numbers of STC 2 mRNA copies were significantly higher in the gastric cancer cell lines and in blood from patients with gastric cancer than in blood from healthy volunteers $(\mathrm{P}=0.0002$ and $\mathrm{P}=0.01$, respectively). STC2 expression was positive in $43(46.2 \%)$ of the 93 patients with gastric cancer, and its expression was significantly correlated with age, depth of tumor invasion, lymph node metastasis, stage and venous invasion $(\mathrm{P}=0.023, \mathrm{P}=0.045, \mathrm{P}=0.035$, $\mathrm{P}=0.007$ and $\mathrm{P}=0.027$, respectively). The 5-year survival rate was significantly lower in patients with STC2 expression compared to patients without STC2 expression $(\mathrm{P}=0.014)$. Our results indicate that STC2 could be a useful molecular blood
\end{abstract}

Correspondence to: Dr Takaaki Arigami, Department of Digestive Surgery, Breast and Thyroid Surgery, Field of Oncology, Course of Advanced Therapeutics, Kagoshima University Graduate School of Medical and Dental Sciences, 8-35-1 Sakuragaoka, Kagoshima 890-8520, Japan

E-mail: arigami@m.kufm.kagoshima-u.ac.jp

Key words: stanniocalcin 2, tumor progression, prognosis, reverse transcription-polymerase chain reaction, gastric cancer marker for predicting tumor progression by monitoring CTCs in patients with gastric cancer.

\section{Introduction}

Gastric cancer is the most common malignancy in Asia and is the third leading cause of cancer-related deaths in Japan (1-3). Endoscopic treatments, such as endoscopic mucosal resection and endoscopic submucosal dissection (ESD), have been recently performed in selected patients with early gastric cancer. At present, the expanded ESD indication for patients with early gastric cancer is under discussion (4). In regards to surgical procedures, laparoscopic gastrectomy has been frequently carried out as minimally invasive surgery in patients with early gastric cancer. Furthermore, the 5-year survival rates of patients with mucosal and submucosal gastric cancer are 95-100 and 85-95\%, respectively (5-7). Thus, these findings imply that there is a spread of therapeutic options for the clinical management of early gastric cancer patients with good outcome. On the other hand, new anticancer agents for patients with unresectable advanced or recurrent gastric cancer have been developed, and trastuzumab has been focused on as a novel molecular-targeted drug for patients with human epidermal growth factor receptor 2 (HER2)-positive advanced gastric cancer (8). Nevertheless, the prognosis of such patients is still poor even when receiving novel chemotherapy. Therefore, it is important to diagnose patients at an early stage of gastric cancer and to identify post-operative patients at high risk for disease recurrence in clinical management. Although tumor markers such as carcinoembryonic antigen (CEA) and carbohydrate antigen 19-9 (CA19-9) are currently used in the blood examination of patients with gastric cancer, the identification of further molecular blood markers is a prerequisite for the clinical management of patients with gastric cancer.

Stanniocalcins (STCs) are glycoprotein hormones that were originally identified in bony fish $(9,10)$. Moreover, several investigators have reported that STCs play an important role in calcium and phosphate homeostasis (11-14). STC2 is one member of the STC family, and recent findings have 
demonstrated that it is a hypoxia-inducible factor 1 (HIF-1) target gene that promotes cell proliferation, invasion and epithelial-mesenchymal transition (EMT) in hypoxia $(15,16)$. STC2 is expressed at high levels in tumor cells of malignancies such as neuroblastoma, esophageal, gastric, colorectal, ovarian, prostate, breast and renal cell cancers (16-23). The status of STC2 expression in these tumor cells of the primary site is closely correlated with tumor progression, including prognosis. However, the clinical significance of STC2 expression in the blood of patients with gastric cancer has not yet been determined.

The aim of the present study was to assess STC2 expression in blood specimens from patients with gastric cancer and to investigate the relationship between STC2 expression and clinicopathological factors including prognosis in patients with gastric cancer.

\section{Materials and methods}

Gastric cancer cell lines. Four gastric cancer cell lines (MKN-7, MKN-45, MKN-74 and KATO-III) were cultured in RPMI-1640 (Nissui Pharmaceutical Co., Ltd., Tokyo, Japan) supplemented with $10 \%$ fetal calf serum (Mitsubishi Kasei, Tokyo, Japan), as well as 100 units $/ \mathrm{ml}$ each of penicillin and streptomycin at $37^{\circ} \mathrm{C}$ in a humidified atmosphere containing $5 \% \mathrm{CO}_{2}$, as described previously $(24,25)$. These cell lines were used for reverse transcription-polymerase chain reaction (RT-PCR) assay.

Patients. Blood specimens were obtained preoperatively from 93 patients (64 men and 29 women; age range, 35-87 years; average age, 68 years) with gastric cancer who underwent curative gastrectomy with lymph node dissection at Kagoshima University Hospital (Kagoshima, Japan) between 2003 and 2005. None of the patients had received endoscopic mucosal resection, palliative resection, preoperative chemotherapy, and/or radiotherapy in the present study. Furthermore, patients who had synchronous or metachronous cancer in other organs were excluded. Patients were classified and staged on the basis of criteria of the tumor-node-metastasis (TNM) classification of gastric carcinoma established by the International Union Against Cancer (UICC) (26). Normal peripheral blood lymphocytes (PBLs) isolated from 22 healthy volunteers were used as a control group. After discharge, all patients were followed up every 3-6 months by blood tumor marker studies (CEA and CA19-9), radiography, ultrasonography and computed tomography at Kagoshima University Hospital. The median follow-up period after surgery was 25 months (range, 1-74 months).

To investigate STC2 protein expression in gastric cancer, 30 paraffin-embedded archival tissue (PEAT) specimens of resected primary gastric tumors from patients enrolled in this study were used for immunohistochemical analysis.

All specimens were collected from patients after informed consent was obtained in accordance with the institutional guidelines of our hospital.

Blood processing and RNA extraction for RT-PCR analysis. Blood specimens $(5 \mathrm{ml})$ from each patient were preoperatively collected in tubes containing sodium citrate, and then blood cells were separated in lymphocyte separation buffer (Gentra Systems, Inc., Minneapolis, MN, USA). Total RNA was extracted from the cell lines and blood specimens using Isogen (Nippon Gene, Toyama, Japan). Total RNA was isolated and purified using phenol-chloroform extraction as previously described $(24,25)$. The concentration and purity of the total RNA were determined using a GeneQuant Pro $\mathrm{UV} / \mathrm{V}$ is spectrophotometer (Amersham Pharmacia Biotech, Cambridge, UK).

Primers and probes. Primer and probe sequences of STC2 and glyceraldehyde-3-phosphatase dehydrogenase (GAPDH) were designed for RT-PCR assays of each marker. The forward primers, fluorescence resonance energy transfer probe sequence, and reverse primers for STC2 and GAPDH were as follows: STC2 forward, 5'-GACTTGCTGCTGCACGAAC-3'; probe, 5'-FAM-ACGTGGACCTCGTGAACTTGCTG-TAM RA-1-3'; reverse, 5'-TGCTCACACTGAACCTGCAC-3' and GAPDH forward, 5'-GGGTGTGAACCATGAGAAGT-3'; probe, 5'-FAM-CAGCAATGCCTCCTGCACCACCAA-TA MRA-1-3'; reverse, 5'-GACTGTGGTCATGAGTCCT-3'. The RT-PCR products for STC2 and GAPDH were resolved as 107- and 136- base pair fragments, respectively. The integrity of the RNA was confirmed by RT-PCR assay using GAPDH.

Quantitative RT-PCR assay. All total RNA samples were reverse-transcribed using the Advantage RT-for-PCR kit (Clontech Laboratories, Inc., Palo Alto, CA, USA) as previously described $(24,25)$. Quantitative RT-PCR (qRT-PCR) proceeded using the LightCycler System (Roche Diagnostics, Mannheim, Germany). The reaction mixtures contained cDNA transcribed from 250 ng of RNA using each primer, probe, $\mathrm{MgCl}_{2}$, and LightCycler FastStart DNA Master hybridization probes (Roche Diagnostics). The amplification profile comprised precycling at $95^{\circ} \mathrm{C}$ for $10 \mathrm{~min}$ followed by 40 cycles of denaturation at $95^{\circ} \mathrm{C}$ for $10 \mathrm{sec}$, annealing for $20 \mathrm{sec}\left(60^{\circ} \mathrm{C}\right.$ for $\mathrm{STC} 2$, and $55^{\circ} \mathrm{C}$ for GAPDH), and extension at $72^{\circ} \mathrm{C}$ for $10 \mathrm{sec}$. Plasmids for each marker were synthesized using pT7Blue-2 T-Vector (Novagen, Madison, WI, USA) according to the manufacturer's instructions. Standard curves for each assay were generated using the threshold cycles of 6 serial dilutions of plasmid templates $\left(10^{6}-10^{1}\right.$ copies). The mRNA copy number was determined using LightCycler software (Roche Diagnostics). Each assay was repeated in duplicate with positive (cell line), negative $\left(\mathrm{H}_{2} \mathrm{O}\right)$, and reagent (without cDNA) controls to evaluate the quality of the qRT-PCR assay. Absolute copy numbers in qRT-PCR assays were computed on the basis of standard curves of plasmid templates. Copy numbers of STC2 mRNA were normalized by those of GAPDH mRNA (relative STC2 mRNA copies; absolute STC2 mRNA copies/absolute GAPDH mRNA copies).

Cell spiking study for determining the sensitivity of the RT-PCR assay. Serial dilutions $\left(10^{4}, 10^{3}, 10^{2}, 10^{1}\right.$ and 0$)$ of MKN-74 tumor cells mixed with $1 \times 10^{7}$ PBLs, which were isolated from a healthy volunteer without STC2 mRNA expression, were used for determining the sensitivity of the qRT-PCR analysis. This in vitro assay was repeated 3 times to verify its reproducibility. 


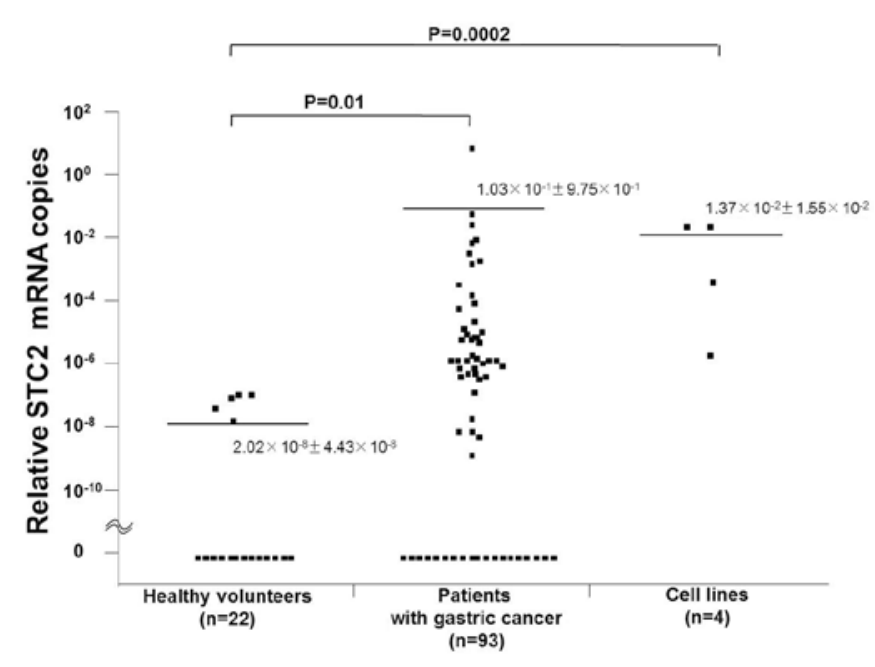

Figure 1. RT-PCR analysis of STC2 mRNA expression in cell lines and in blood specimens from patients with gastric cancer and healthy volunteers. Horizontal bars indicate mean STC2 mRNA copy numbers. STC2, stanniocalcin 2 .

Immunohistochemical staining. The PEAT sections $(3 \mu \mathrm{m})$ of surgical primary gastric tumors were incubated on slides at $50^{\circ} \mathrm{C}$ overnight, deparaffinized with xylene and then rehydrated with a graded series of ethanol. The sections were autoclaved in citrate buffer $(0.01 \mathrm{~mol} / 1, \mathrm{pH} 6.0)$ at $120^{\circ} \mathrm{C}$ for $10 \mathrm{~min}$ to activate the antigen. After cooling at room temperature, endogenous peroxidase was blocked using a peroxidase blocking reagent (DakoCytomation, Carpinteria, CA, USA) for $10 \mathrm{~min}$. Non-specific binding was blocked at room temperature for $30 \mathrm{~min}$ with Protein Block Serum-Free (DakoCytomation). The sections were incubated at room temperature for $60 \mathrm{~min}$ with an anti-human STC2 polyclonal antibody (Proteintech Group, Inc., Chicago, IL, USA) diluted 1:200 in Dako antibody diluent with background reducing components (DakoCytomation). After three 5-min washes in phosphate-buffered saline (PBS), the reaction for STC2 was developed by the ABC method (Vectastain ABC kit; Vector Laboratories) and visualized using diaminobenzidine tetrahydrochloride (DakoCytomation). Negative controls were treated with PBS without the primary antibody under the same conditions. On the basis of immunostainable intensity, STC2 immunoreactivity was classified into 3 groups: negative, weak, and strong immunoreactions.

Statistical analysis. Differences in STC2 mRNA expression between gastric cancer cell lines and PBLs from healthy volunteers, and between PBLs from patients with gastric cancer and healthy volunteers, were evaluated by the Wilcoxon rank-sum test. The relationship between the status of STC2 expression and categorical clinicopathological factors was assessed by the Chi-square and Fisher's exact tests. Survival curves were generated using the Kaplan-Meier method, and differences in survival were examined using the log-rank test. Prognostic factors were assessed by univariate and multivariate analyses (Cox proportional hazard regression model). All statistical calculations were performed using SAS statistical software (SAS Institute Inc., Cary, NC, USA). A P-value of $<0.05$ was considered to indicate a statistically significant result.

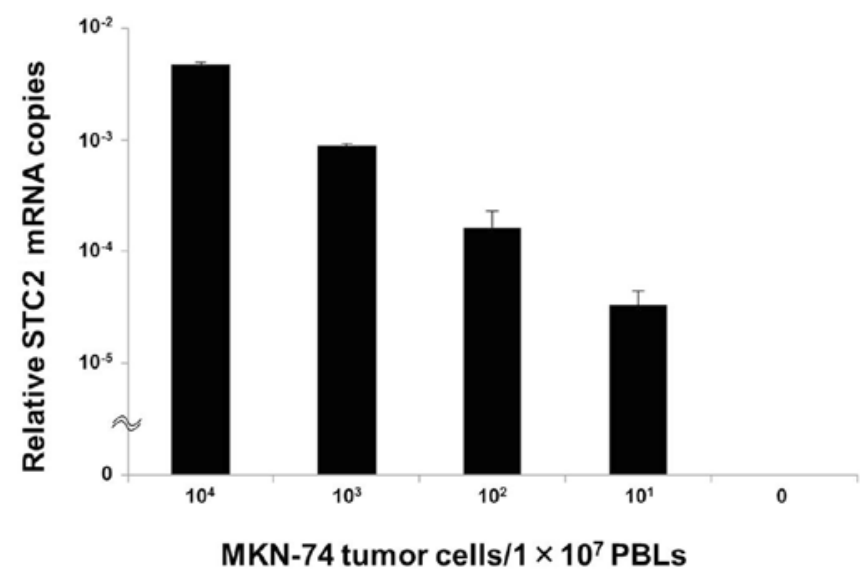

Figure 2. RT-PCR analysis of STC2 mRNA expression in cell spiking study. Serially diluted MKN-74 tumor cells $\left(10^{4}, 10^{3}, 10^{2}, 10^{1}\right.$ and 0$)$ were mixed with normal PBLs. Bars indicate standard deviation (SD). STC2, stanniocalcin 2; PBLs, peripheral blood lymphocytes.

\section{Results}

STC2 mRNA expression determined by RT-PCR in cell lines and clinical blood specimens. STC2 mRNA expression in 4 gastric cancer cell lines, blood specimens from 93 patients with gastric cancer, and from 22 healthy volunteers without cancers was assessed by qRT-PCR.

The range of relative STC2 mRNA copies was $2.49 \times 10^{-6}$ to $2.75 \times 10^{-2}$ in gastric cancer cell lines, 0 to 9.4 in blood from patients, and 0 to $1.35 \times 10^{-7}$ in normal PBLs from healthy volunteers. The mean relative numbers of STC2 mRNA copies $( \pm \mathrm{SD})$ were $1.37 \times 10^{-2} \pm 1.55 \times 10^{-2}$ in gastric cancer cell lines, $1.03 \times 10^{-1} \pm 9.75 \times 10^{-1}$ in blood from patients, and $2.02 \times 10^{-8} \pm 4.43 \times 10^{-8}$ in normal PBLs (Fig. 1). Accordingly, the relative numbers of STC 2 mRNA copies were significantly higher in the gastric cancer cell lines and in blood from patients than in normal PBLs $(\mathrm{P}=0.0002$ and $\mathrm{P}=0.01$, respectively). STC2 mRNA expression was identified in 43 (46.2\%) of the 93 patients with gastric cancer.

STC2 mRNA expression in the cell spiking study. This spiking study was planned to investigate the relationship between STC2 mRNA expression and the number of tumor cells in an in vitro assay.

STC2 expression was identified in MKN-74 cells at a density of $10^{1}$ tumor cells $/ 1 \times 10^{7} \mathrm{PBLs}$, and the relative numbers of STC2 mRNA copies gradually decreased as the numbers of tumor cells within normal PBLs decreased (Fig. 2).

Relationship between STC2 expression and the clinicopathological features of the gastric cancer patients. All patients were classified into 2 groups based on the status of STC2 expression (positive, $n=43$; negative, $n=50$ ) to evaluate the relationship between STC2 expression and clinicopathological features.

STC2 expression was significantly correlated with age, depth of tumor invasion, lymph node metastasis, stage and venous invasion $(\mathrm{P}=0.023, \mathrm{P}=0.045, \mathrm{P}=0.035, \mathrm{P}=0.007$ and $\mathrm{P}=0.027$, respectively; Table I). 
Table I. Relationship between STC2 expression and clinicopathological features in patients with gastric cancer.

\begin{tabular}{|c|c|c|c|}
\hline \multirow[b]{2}{*}{ Features } & \multicolumn{2}{|c|}{ STC2 expression, n (\%) } & \multirow[b]{2}{*}{ P-value } \\
\hline & $\begin{array}{l}\text { Negative } \\
(n=50)\end{array}$ & $\begin{array}{c}\text { Positive } \\
(n=43)\end{array}$ & \\
\hline \multicolumn{4}{|l|}{ Gender } \\
\hline Male & $35(70.0)$ & $29(67.4)$ & 0.825 \\
\hline Female & $15(30.0)$ & $14(32.6)$ & \\
\hline \multicolumn{4}{|l|}{ Age (years) } \\
\hline$\leq 70$ & $31(62.0)$ & $16(37.2)$ & 0.023 \\
\hline$>70$ & $19(38.0)$ & $27(62.8)$ & \\
\hline \multicolumn{4}{|l|}{ Tumor location } \\
\hline Upper & $15(30.0)$ & $16(37.2)$ & 0.540 \\
\hline Middle & $18(36.0)$ & $11(25.6)$ & \\
\hline Lower & $17(34.0)$ & $16(37.2)$ & \\
\hline \multicolumn{4}{|l|}{ Histological type } \\
\hline Differentiated & $27(54.0)$ & $19(44.2)$ & 0.408 \\
\hline Undifferentiated & $23(46.0)$ & $24(55.8)$ & \\
\hline \multicolumn{4}{|c|}{ Depth of tumor invasion } \\
\hline pT1-T2 & $21(42.0)$ & $9(20.9)$ & 0.045 \\
\hline pT3-T4 & $29(58.0)$ & $34(79.1)$ & \\
\hline \multicolumn{4}{|c|}{ Lymph node metastasis } \\
\hline Negative & $25(50.0)$ & $12(27.9)$ & 0.035 \\
\hline Positive & $25(50.0)$ & $31(72.1)$ & \\
\hline \multicolumn{4}{|l|}{ Distant metastasis } \\
\hline Negative & $43(86.0)$ & $36(83.7)$ & 0.779 \\
\hline Positive & $7(14.0)$ & $7(16.3)$ & \\
\hline \multicolumn{4}{|l|}{ Stage } \\
\hline I-II & $32(64.0)$ & $15(34.9)$ & 0.007 \\
\hline III-IV & $18(36.0)$ & $28(65.1)$ & \\
\hline \multicolumn{4}{|l|}{ Lymphatic invasion } \\
\hline Negative & $20(40.0)$ & $10(23.3)$ & 0.119 \\
\hline Positive & $30(60.0)$ & $33(76.7)$ & \\
\hline \multicolumn{4}{|l|}{ Venous invasion } \\
\hline Negative & $22(44.0)$ & $9(20.9)$ & 0.027 \\
\hline Positive & $28(56.0)$ & $34(79.1)$ & \\
\hline
\end{tabular}

pT1, invasion of lamina propria or submucosa; pT2, invasion of muscularis propria; pT3, invasion of subserosa; pT4, penetration of serosa without invasion of adjacent structures or invasion of adjacent structures. STC2, stanniocalcin 2.

Relationship between STC2 expression and prognosis. The 5-year survival rates were 58.4 and $80.9 \%$ in patients with STC2-positive and -negative expression, respectively (Fig. 3). Five-year survival rates were significantly lower in patients with STC2-positive expression than in those with STC2-negative expression ( $\mathrm{P}=0.014$; Fig. 3 ).

Univariate analysis demonstrated that age, depth of tumor invasion, lymph node metastasis, distant metastasis, lymphatic invasion, venous invasion and STC2 expression were

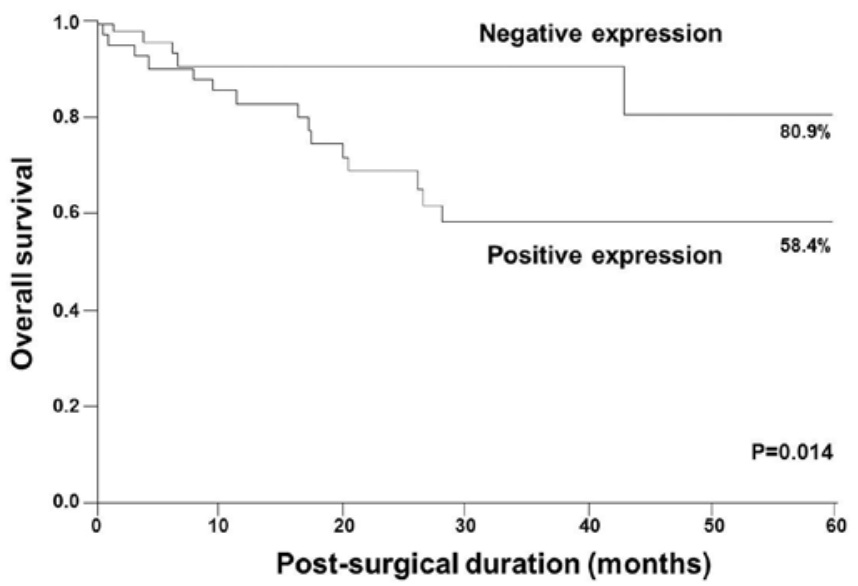

Figure 3. Kaplan-Meier survival curves for patients with gastric cancer based on the status of STC2 expression. Patients with STC2-positive expression had a significantly poorer prognosis than those with STC2-negative expression $(\mathrm{P}=0.014)$. STC2, stanniocalcin 2.

significantly correlated with postoperative survival $(\mathrm{P}=0.020$, $\mathrm{P}=0.003, \mathrm{P}=0.002, \mathrm{P}=0.046, \mathrm{P}=0.030, \mathrm{P}=0.041$ and $\mathrm{P}=0.012$, respectively; Table II). Multivariate analysis demonstrated that age, lymph node metastasis and distant metastasis were independent prognostic factors $(\mathrm{P}=0.002, \mathrm{P}=0.024$ and $\mathrm{P}=0.047$, respectively; Table II). Consequently, STC2 expression was not an independent prognostic factor in the multivariate analysis $(\mathrm{P}=0.433)$.

STC2 protein expression as determined by immunohistochemistry in primary tumor specimens. To confirm STC2 expression in primary tumor sites, immunohistochemical evaluation was carried out on 30 surgical PEAT specimens of primary gastric tumors. Immunohistochemical analysis showed that STC2 protein expression was identified in the membrane and/or cytoplasm of gastric tumor cells (Fig. 4). Furthermore, primary gastric tumors had various immunoreactions for STC2 (Fig. 4A-C). Finally, strong immunoreaction was identified in $46.7 \%$ (7/15) and $26.7 \%$ (4/15) of patients with STC2-positive and -negative mRNA expression, respectively.

\section{Discussion}

In the present study, we investigated STC2 mRNA expression in blood from patients with gastric cancer using qRT-PCR assay. Furthermore, we also compared the relationship between the status of STC2 expression and clinicopathological findings to assess the clinical impact of STC2 expression as a useful blood marker in patients with gastric cancer. To our knowledge, this is the first study regarding STC2 expression in circulating tumor cells (CTCs) obtained from patients with gastric cancer.

To date, STC2 expression has been identified in various malignant diseases (16-23). In the present study, STC2 protein expression in gastric tumor cells was verified by immunohistochemical analysis. Furthermore, we confirmed STC2 mRNA expression in all gastric cancer cell lines and demonstrated STC2 mRNA high expression in blood from patients with gastric cancer. Although STC2 mRNA expression was 
Table II. Univariate and multivariate analyses of survival in patients with gastric cancer.

\begin{tabular}{|c|c|c|c|c|c|c|}
\hline \multirow[b]{2}{*}{ Independent factor } & \multicolumn{3}{|c|}{ Univariate analysis } & \multicolumn{3}{|c|}{ Multivariate analysis } \\
\hline & Hazard ratio & $95 \%$ CI & P-value & Hazard ratio & $95 \%$ CI & P-value \\
\hline \multicolumn{7}{|l|}{ Age (years) } \\
\hline$\leq 70 />70$ & 1.719 & $1.088-2.890$ & 0.020 & 2.272 & $1.342-4.110$ & 0.002 \\
\hline \multicolumn{7}{|c|}{ Depth of tumor invasion } \\
\hline pT1-T2/pT3-T4 & 2.417 & $1.300-6.066$ & 0.003 & 2.281 & $0.920-7.145$ & 0.080 \\
\hline \multicolumn{7}{|c|}{ Lymph node metastasis } \\
\hline Negative/positive & 2.257 & $1.306-4.674$ & 0.002 & 2.812 & $1.126-9.038$ & 0.024 \\
\hline \multicolumn{7}{|l|}{ Distant metastasis } \\
\hline Negative/positive & 1.700 & $1.010-2.690$ & 0.046 & 1.813 & $1.008-3.186$ & 0.047 \\
\hline \multicolumn{7}{|l|}{ Lymphatic invasion } \\
\hline Negative/positive & 1.821 & $1.055-3.771$ & 0.030 & 0.851 & $0.429-2.035$ & 0.687 \\
\hline \multicolumn{7}{|l|}{ Venous invasion } \\
\hline Negative/positive & 1.763 & $1.021-3.650$ & 0.041 & 0.491 & $0.182-1.486$ & 0.200 \\
\hline \multicolumn{7}{|l|}{ STC2 expression } \\
\hline Negative/positive & 1.820 & $1.132-3.190$ & 0.012 & 1.234 & $0.740-2.225$ & 0.433 \\
\hline
\end{tabular}

pT1, invasion of lamina propria or submucosa; pT2, invasion of muscularis propria; pT3, invasion of subserosa; pT4, penetration of serosa without invasion of adjacent structures or invasion of adjacent structures. STC2, stanniocalcin 2.
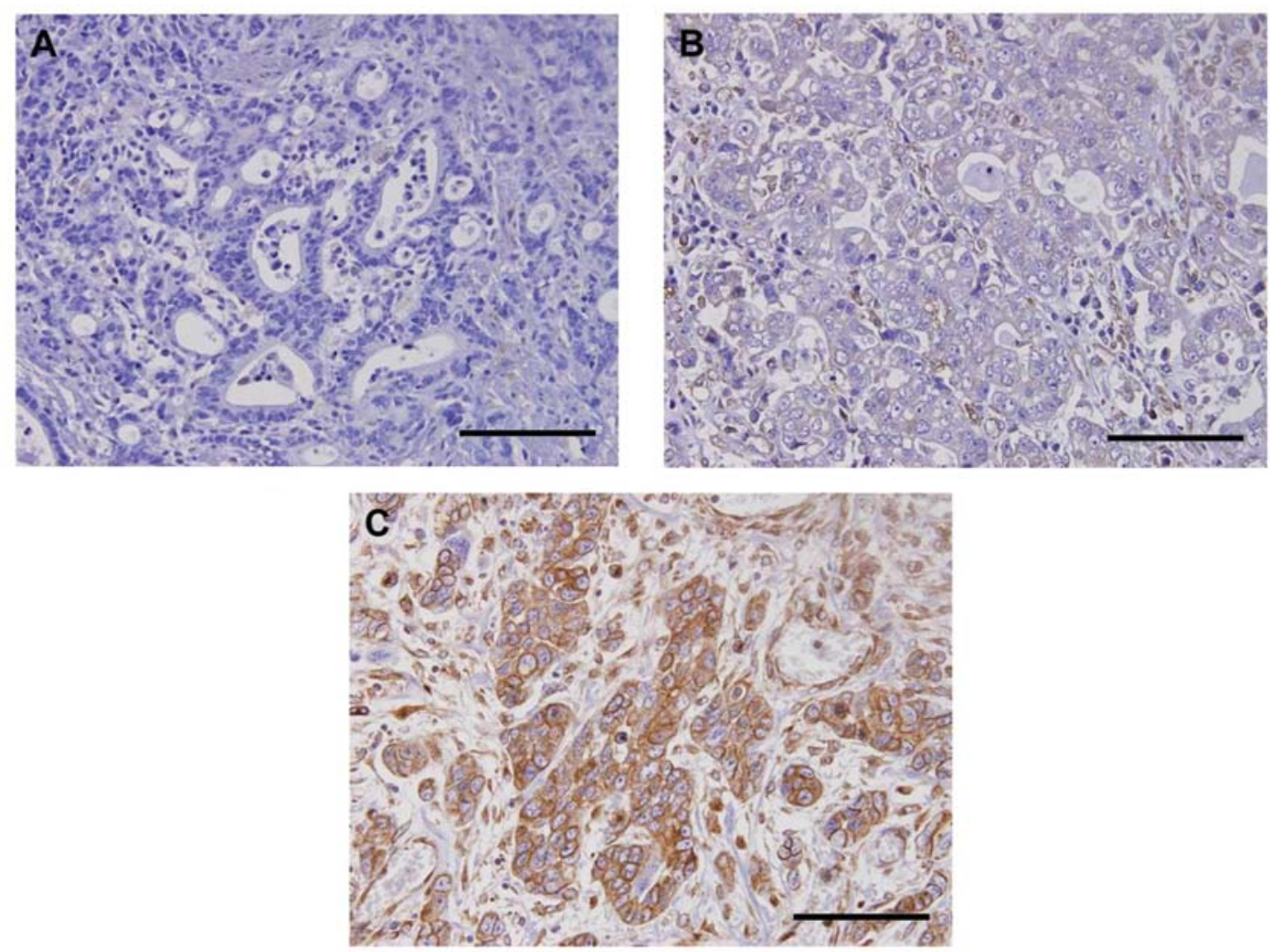

Figure 4. Representative immunohistochemical staining of STC2 expression in primary gastric tumor specimens. (A) Tumor cells with negative expression of STC2. (B) Tumor cells with weak expression of STC2. (C) Tumor cells with strong expression of STC2. Scale bar, $100 \mu \mathrm{m}$. Original magnification, x400. STC2, stanniocalcin 2 .

detected in a few blood specimens from healthy volunteers, the level of STC2 mRNA expression in these specimens was extremely low in comparison with the level in blood specimens from gastric cancer patients. These results indicate the 
clinical utility of RT-PCR assay against the STC2 molecule for discriminating gastric cancer patients from healthy volunteers.

Previous studies have demonstrated the clinical efficacy of CTC detection for predicting the potential for tumor progression and the response to chemotherapy in patients with various types of malignancies (27-30). Furthermore, a CTC assay system using immunomagnetics has been developed as a promising novel tool in recent years (31-33). In gastric cancer, epithelial markers such as cytokeratin and CEA are usually used for CTC detection in RT-PCR assay (28). Miyazono et al (28) reported that the CEA mRNA-positive rate in patients with gastric cancer was $36.8 \%$, and CEA mRNA positivity was significantly correlated with the depth of tumor invasion and recurrence. In the present study, we showed the intensive relationship between the status of STC2 expression and tumor progression, such as depth of tumor invasion, lymph node metastasis, stage and venous invasion. Moreover, we verified the positive correlation between STC2 mRNA copies and the number of gastric tumor cells in a cell spiking study. At present, potential blood markers for monitoring CTCs are limited in the clinical management of patients with gastric cancer. Consequently, STC2 could be one of the surrogate markers for predicting tumor progression in patients with gastric cancer.

Although the functional role of STC2 remains unclear, several investigators have demonstrated the positive effects of STC2 induced by hypoxia in an in vitro study $(15,16)$. Law and Wong (16) reported that STC2 overexpression enhanced the process of EMT via an increase in $\mathrm{N}$-cadherin and vimentin and a reduction in E-cadherin in hypoxic human ovarian cancer cells. Additionally, a potentially relevant association was found between STC2 expression and matrix metalloproteases involved in tumor invasion in hypoxia (16). In the present study, STC2 overexpression was significantly correlated with tumor aggressiveness and poorer prognosis. These results suggest that STC2 is a promising marker for new targeted therapies that suppress tumor progression in patients with gastric cancer.

In conclusion, we demonstrated that STC2 is overexpressed in blood from patients with gastric cancer and that its expression is positively associated with malignant behavior. Therefore, STC2 is available for predicting tumor progression by monitoring CTCs in patients with gastric cancer. Further understanding of its functional role would allow the development of an attractive treatment strategy for patients with gastric cancer.

\section{Acknowledgements}

We thank Ms. Y. Nishizono and Ms. M. Motomura for their technical assistance. This study was supported in part by a Grant-in-Aid (no. 25461955) for Scientific Research from the Ministry of Education, Science, Sports and Culture, Japan.

\section{References}

1. Statistics and Information Department, Ministry of Health, Labour, and Welfare: Vital Statistics of Japan 2004. Tokyo: Health and Welfare Statistics Association, 2006.

2. Katanoda $\mathrm{K}$ and Yako-Suketomo H: Comparison of time trends in stomach cancer incidence (1973-2002) in Asia, from Cancer Incidence in Five Continents, Vols IV-IX. Jpn J Clin Oncol 39: 71-72, 2009.
3. Li ZX and Kaminishi M: A comparison of gastric cancer between Japan and China. Gastric Cancer 12: 52-53, 2009.

4. Lee H, Yun WK, Min BH, et al: A feasibility study on the expanded indication for endoscopic submucosal dissection of early gastric cancer. Surg Endosc 25: 1985-1993, 2011.

5. Maehara Y, Orita H, Okuyama T, Moriguchi S, Tsujitani S, Korenaga D and Sugimachi K: Predictors of lymph node metastasis in early gastric cancer. Br J Surg 79: 245-247, 1992.

6. Cai J, Ikeguchi M, Maeta M and Kaibara N: Micrometastasis in lymph nodes and microinvasion of the muscularis propria in primary lesions of submucosal gastric cancer. Surgery 127 : 32-39, 2000.

7. Kim DY, Joo JK, Ryu SY, Kim YJ and Kim SK: Factors related to lymph node metastasis and surgical strategy used to treat early gastric carcinoma. World J Gastroenterol 10: 737-740, 2004.

8. Bang YJ, Van Cutsem E, Feyereislova A, et al: Trastuzumab in combination with chemotherapy versus chemotherapy alone for treatment of HER2-positive advanced gastric or gastrooesophageal junction cancer (ToGA): a phase 3 , open-label, randomised controlled trial. Lancet 376: 687-697, 2010.

9. Chang AC, Janosi J, Hulsbeek M, de Jong D, Jeffrey KJ, Noble JR and Reddel RR: A novel human cDNA highly homologous to the fish hormone stanniocalcin. Mol Cell Endocrinol 112: 241-247, 1995.

10. Chang AC, Jeffrey KJ, Tokutake Y, et al: Human stanniocalcin (STC): genomic structure, chromosomal localization, and the presence of CAG trinucleotide repeats. Genomics 47: 393-398, 1998.

11. Wagner GF, Jaworski EM and Haddad M: Stanniocalcin in the seawater salmon: structure, function, and regulation. Am J Physiol 274: R1177-R1185, 1998.

12. Chang AC and Reddel RR: Identification of a second stanniocalcin cDNA in mouse and human: stanniocalcin 2. Mol Cell Endocrinol 141: 95-99, 1998.

13. Ishibashi $\mathrm{K}$ and Imai $\mathrm{M}$ : Prospect of a stanniocalcin endocrine/paracrine system in mammals. Am J Physiol Renal Physiol 282: F367-F375, 2002.

14. Chang AC, Jellinek DA and Reddel RR: Mammalian stanniocalcins and cancer. Endocr Relat Cancer 10: 359-373, 2003.

15. Law AY and Wong CK: Stanniocalcin-2 is a HIF-1 target gene that promotes cell proliferation in hypoxia. Exp Cell Res 316: 466-476, 2010

16. Law AY and Wong CK: Stanniocalcin-2 promotes epithelialmesenchymal transition and invasiveness in hypoxic human ovarian cancer cells. Exp Cell Res 316: 3425-3434, 2010.

17. Bouras T, Southey MC, Chang AC, et al: Stanniocalcin 2 is an estrogen-responsive gene coexpressed with the estrogen receptor in human breast cancer. Cancer Res 62: 1289-1295, 2002.

18. Meyer HA, Tölle A, Jung M, et al: Identification of stanniocalcin 2 as prognostic marker in renal cell carcinoma. Eur Urol 55: 669-678, 2009

19. Tamura K, Furihata M, Chung SY, et al: Stanniocalcin 2 overexpression in castration-resistant prostate cancer and aggressive prostate cancer. Cancer Sci 100: 914-919, 2009.

20. Ieta K, Tanaka F, Yokobori T, et al: Clinicopathological significance of stanniocalcin 2 gene expression in colorectal cancer. Int J Cancer 125: 926-931, 2009.

21. Volland S, Kugler W, Schweigerer L, Wilting J and Becker J: Stanniocalcin 2 promotes invasion and is associated with metastatic stages in neuroblastoma. Int J Cancer 125: 2049-2057, 2009.

22. Yokobori T, Mimori K, Ishii H, et al: Clinical significance of stanniocalcin 2 as a prognostic marker in gastric cancer. Ann Surg Oncol 17: 2601-2607, 2010.

23. Kita Y, Mimori K, Iwatsuki M, et al: STC2: a predictive marker for lymph node metastasis in esophageal squamous-cell carcinoma. Ann Surg Oncol 18: 261-272, 2011.

24. Arigami T, Natsugoe S, Uenosono Y, et al: Lymphatic invasion using D2-40 monoclonal antibody and its relationship to lymph node micrometastasis in pN0 gastric cancer. Br J Cancer 93: 688-693, 2005.

25. Arigami T, Natsugoe S, Uenosono Y, et al: Evaluation of sentinel node concept in gastric cancer based on lymph node micrometastasis determined by reverse transcription-polymerase chain reaction. Ann Surg 243: 341-347, 2006.

26. Edge SB, Byrd DR, Compton CC, Fritz AG, Greene FL and Trotti A (eds): American Joint Committee on Cancer (AJCC). In: Cancer Staging Manual. 7th edition. Springer, New York, NY, p649, 2010 
27. Hoon DS, Bostick P, Kuo C, Okamoto T, Wang HJ, Elashoff R and Morton DL: Molecular markers in blood as surrogate prognostic indicators of melanoma recurrence. Cancer Res 60: 2253-2257, 2000.

28. Miyazono F, Natsugoe S, Takao S, et al: Surgical maneuvers enhance molecular detection of circulating tumor cells during gastric cancer surgery. Ann Surg 233: 189-194, 2001.

29. Uen YH, Lin SR, Wu DC, et al: Prognostic significance of multiple molecular markers for patients with stage II colorectal cancer undergoing curative resection. Ann Surg 246: 1040-1046, 2007.

30. Ignatiadis M, Kallergi G, Ntoulia M, et al: Prognostic value of the molecular detection of circulating tumor cells using a multimarker reverse transcription-PCR assay for cytokeratin 19, mammaglobin A, and HER2 in early breast cancer. Clin Cancer Res 14: 2593-2600, 2008.
31. Cristofanilli M, Budd GT, Ellis MJ, et al: Circulating tumor cells, disease progression, and survival in metastatic breast cancer. N Engl J Med 351: 781-791, 2004.

32. Cohen SJ, Punt CJ, Iannotti N, et al: Relationship of circulating tumor cells to tumor response, progression-free survival, and overall survival in patients with metastatic colorectal cancer. J Clin Oncol 26: 3213-3221, 2008.

33. Krebs MG, Sloane R, Priest L, et al: Evaluation and prognostic significance of circulating tumor cells in patients with non-smallcell lung cancer. J Clin Oncol 29: 1556-1563, 2011. 